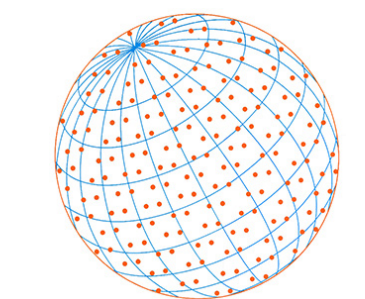

Aerosol and Air Quality Research

\title{
Performance Evaluation of Real-time DustTrak Monitors for Outdoor Particulate Mass Measurements in a Desert Environment
}

\author{
Wasim Javed", Bing Guo \\ Mechanical Engineering Program, Texas A\&M University at Qatar, Doha, Qatar
}

\section{ABSTRACT}

Using the filter-based gravimetric technique as the reference method, this study aimed to evaluate the performance of the TSI DustTrak DRX ${ }^{\circledR}$ aerosol monitor, which offers real-time measurements, and establish suitable factors for bias correction in real-world operating conditions. Overall, the DustTrak demonstrated high precision in tracking the $\mathrm{PM}_{2.5}$ and $\mathrm{PM}_{10}$ mass concentrations; however, the measurements significantly deviated from those obtained via the reference method, showing an overestimation by a factor of $\sim 2$ for the fine fraction and an underestimation by $\sim 20 \%$ for the coarse one. Applying a correction factor based on a constant proportion produced an acceptable level of accuracy, but utilizing one adjusted for humidity achieved even better results. These factors can also be used to enhance the accuracy of DustTrak measurements under comparable conditions, i.e., for aerosol with similar properties in similar environments. Additionally, the proposed approaches can serve as a model for field calibration and measurement data correction in other studies employing various types of real-time optical monitors.

Keywords: Correction factor, Accuracy, Precision, Relative humidity, Particle composition

\section{INTRODUCTION}

\section{OPEN ACCESS}

Received: November 16, 2020 Revised: January 21, 2021 Accepted: February 16, 2021

${ }^{*}$ Corresponding Author: wasim.javed@qatar.tamu.edu

\section{Publisher:}

Taiwan Association for Aerosol Research

ISSN: $1680-8584$ print ISSN: 2071-1409 online

Copyright: The Author(s). This is an open access article distributed under the terms of the Creative Commons Attribution License (CC BY 4.0), which permits unrestricted use, distribution, and reproduction in any medium, provided the original author and source are cited.

Airborne particulate matter (PM), as a major air pollutant, has well-reported adverse health effects, including respiratory, cardiovascular, and neurological problems and premature mortality (Anderson et al., 2012). Therefore, the PM mass concentrations, particularly $\mathrm{PM}_{2.5}$ and $\mathrm{PM}_{10}$ particles (aerodynamic diameter $\leq 2.5$ and $\leq 10 \mu \mathrm{m}$, respectively), are routinely monitored and regulated by establishing air quality monitoring networks to enforce PM concentration standards by governments and regulatory agencies. Over the past two decades, portable real-time optical aerosol monitors and sensors have found increasing use in air quality monitoring (Liu et al., 2017; Zhang et al., 2018). These monitors offer numerous advantages over the reference filter-based samplers. Traditional gravimetric samplers are accurate, reliable, and robust devices for determining the PM mass concentration and its detailed characteristics. However, this reference sampling technique is expensive, labor-intensive, and time-consuming. It requires long sampling and analysis time and hence does not provide real-time information (Chung et al., 2001).

The optical aerosol monitors for measuring airborne PM concentrations (e.g., the TSI DustTrak ${ }^{\circledR}$ aerosol monitor) are based on light scattering to detect light scattered by particles onto a photodetector (Wang et al., 2009; Wang et al., 2016; TSI Inc., 2019). These light-scattering aerosol monitors can provide high spatiotemporal resolution as they are very portable and capable of reporting PM concentration in nearly real-time. These direct-reading monitors can report high PM concentration spikes and short-term peak events, which could be essential for emergency responses, public health advisories, and regulatory purposes. Due to the high portability, these real-time monitors can be used to locate pollution hotspots and generate three-dimensional (horizontal and vertical) aerosol profiles, and also measure aerosol PM exposure characteristics 
in different indoor micro-environments where people spend most of their time, such as in buildings and transit (McNamara et al., 2011; Wheeler et al., 2014; Wang et al., 2016; Li et al., 2017). However, before using these aerosol monitors in routine monitoring networks, it is crucial to develop confidence that these instruments are capable of accurately measuring PM concentrations under the prevailing ambient conditions both indoors and outdoors.

Compared to the gravimetric techniques, the performances of light-scattering aerosol monitors, including the DustTrak monitors, are strongly affected by the weather conditions and properties of particles used for calibration and in the ambient environment (Wang et al., 2016; Liu et al., 2017; Li et al., 2019). For example, ambient relative humidity (RH) has been recognized as a key meteorological factor affecting the performance of the DustTrak aerosol monitor (Jayaratne et al., 2018; Li et al., 2019). Moreover, properties of particles (e.g., density, refractive index, size, shape, and chemical composition) also affect the performance of the light-scattering aerosol monitors (Wang et al., 2016; Liu et al., 2017; Zhang et al., 2018). The optical response of the light-scattering instruments for various aerosol components (e.g., sulfate, organic, and elemental carbon) is related to their refractive index, and particles with a larger refractive index result in a higher optical measurement (Zhang et al., 2018). The light-scattering monitors are typically calibrated with particular test dust by the manufacturer, which may or may not represent real-world operating conditions and aerosol characteristics at a given location. The calibration of these aerosol monitors by considering aerosol composition and size is essential to get true measures of airborne PM for a specific application.

Previous studies have provided examples of the measurement correction of light-scattering DustTrak aerosol monitors. Most of these studies employed the correction method with laboratory-generated particles of different sizes and compositions (Liu et al., 2017; Zhang et al., 2018). The results of laboratory studies may not be representative of the performance of aerosol monitors in real-world conditions. A few other studies have reported the performance of DustTrak monitors (Model 8533 and earlier) as compared to reference methods in the indoor environments (Kam et al., 2011; McNamara et al., 2011; Wang et al., 2016) as well as in outdoor field measurements (Apte et al., 2011; Both et al., 2013; Zhang et al., 2018; Li et al., 2019). It has been consistently reported that the DustTrak monitors overestimate $\mathrm{PM}_{2.5}$ compared to the reference method (McNamara et al., 2011; Wallace et al., 2011; Both et al., 2013; Wang et al., 2016; Zhang et al., 2018; Li et al., 2019), but the correction factors vary widely in these studies. As the correction factor is dependent on local aerosol properties and meteorological conditions, it is important to determine it in the region where the instrument is used. Until now, there have been no reports on the correction factor for the DustTrak DRX in ambient conditions in the Middle East.

This study aimed to evaluate the performance of the TSI DustTrak DRX aerosol monitor in terms of accuracy and precision against a filter-based gravimetric method and establish suitable correction factors for the DustTrak DRX monitor in this arid desert environment. The effect of key meteorological factors, in particular $\mathrm{RH}$ and particle composition, were evaluated in realworld operating conditions.

\section{METHODOLOGY}

In this study, side-by-side ambient PM monitoring and filter sampling were carried out from May 18 to December 14, 2015, at the Outdoor Test Facility $\left(25^{\circ} 19^{\prime} 32^{\prime \prime} \mathrm{N}\right.$ and $\left.51^{\circ} 25^{\prime} 59^{\prime \prime} \mathrm{E}\right)$, a research field station located at the Qatar Foundation's Education City premises in Doha, Qatar. The details of the sampling area and site can be found in our previous study (Javed and Guo, 2020a). A broad range of meteorological conditions and PM concentrations were recorded during the study period (as shown in Fig. S1), allowing the evaluation of DustTrak performance under a wide range of atmospheric conditions. The ambient temperature, $\mathrm{RH}$, and wind speed varied from $15-40^{\circ} \mathrm{C}, 18-70 \%$, and $0.64-5.15 \mathrm{~m} \mathrm{~s}^{-1}$, respectively. The prevailing wind direction was from the northwest (38\%).

\subsection{Gravimetric Measurements}

The gravimetric mass measurement of filter samples is used as a reference method for PM mass concentrations. Three types of $24-\mathrm{h} \mathrm{PM}_{2.5}$ and $\mathrm{PM}_{10}$ filter samples were collected simultaneously on 
every second day (09:00-09:00 local time) during the study period $(n=93)$. Samples were weighed and chemically analyzed for PM mass concentrations, OC/EC contents, and water-soluble anions. The weighing was carried out after the filter equilibration (24-h for pre-sampling and 48-h for postsampling weighing), kept at $18-24^{\circ} \mathrm{C}$ temperature and $40 \pm 5 \% \mathrm{RH}$ conditions in the weighing room. The detailed sampling protocol, quality control/assurance, and sample analysis procedures are reported in our recent study (Javed and Guo, 2020a).

$\mathrm{PM}_{2.5}$ and $\mathrm{PM}_{10}$ samples were collected by using low-volume Harvard Impactor samplers equipped with polyurethane foam (PUF) impaction substrates to remove particles bigger than the specified cut-off diameter. The $\mathrm{PM}_{2.5}$ sampler, run at a flow rate of $16.7 \mathrm{~L} \mathrm{~min}^{-1}$, uses two identical impactor stages in series with PUF impaction substrates, and the PM10 sampler (run at $10 \mathrm{~L} \mathrm{~min}^{-1}$ flow rate) has only one impactor stage with PUF substrate. $\mathrm{PM}_{10}$ and $\mathrm{PM}_{2.5}$ samples were collected on Teflon, quartz, and nylon filters for PM gravimetric mass, EC/OC, and nitrate/sulfate anions analysis, respectively. Six sets of filter and field-blank samples and 12 duplicate PM samples (six for $\mathrm{PM}_{2.5}$ and six for $\mathrm{PM}_{10}$ ) for each PM mass, EC/OC, and anions analysis were collected using the pairs of collocated samplers. The reported concentration values of each species are also fieldand filter-blank corrected.

\subsection{DustTrak Measurements and Corrections}

The real-time concentrations of both PM size fractions were also measured simultaneously with a co-located DustTrak DRX ${ }^{\circledR}$ aerosol monitor (Model 8533EP; TSI Inc., Shoreview, MN, USA). The DustTrak DRX monitor is a combined photometer and optical counter instrument that uses a $90^{\circ}$ light-scattering technique. It measures real-time PM mass concentrations corresponding to $\mathrm{PM}_{1}, \mathrm{PM}_{2.5}, \mathrm{PM}_{4}$, and $\mathrm{PM}_{10}$ size fractions having a detection range from 0.001 to $150 \mathrm{mg} \mathrm{m}^{-3}$ with a mass resolution of $\pm 0.1 \%$ of reading or $0.001 \mathrm{mg} \mathrm{m}^{-3}$ (TSI Inc., 2019). The instrument manual does not provide any detail on the accuracy and precision of this direct-reading monitor.

The monitor was deployed next to the filter sampling station at the same height of about $2 \mathrm{~m}$ to ensure that both instruments sampled the same air masses. DustTrak measurements were logged at 2 min intervals and averaged for $24 \mathrm{~h}$ from 09:00 to 09:00 to match data from the gravimetric method. The factory-set flow rate of $3.0 \mathrm{~L} \mathrm{~min} \mathrm{~m}^{-1}$ was used. The monitor was set to auto-zero calibration at 15-min intervals by using an Autozero module (P/N 801690; TSI Inc.). The default calibration factor "Factory Cal" of 1.00 was used. As per the manufacturer, the DustTrak monitors are calibrated to Arizona Road Dust/ISO 12103-1, A1 test dust, which has a particle density of $2.65 \mathrm{~g} \mathrm{~cm}^{-3}$, a refractive index of 1.54, and particle size distribution between 0.1 to $10 \mu \mathrm{m}$ (TSI Inc., 2013). This calibration factor can be changed, or instead, a correction can be made to the raw data based upon comparison with the reference method.

In this study for model calibration and validation, the whole dataset $(n=93)$ was split into two halves by putting the consecutive samples into each half (i.e., one data point into the first half and the next one into the second half, and so forth). The one-half dataset $(n=47)$ was used to develop the correction model, and the second half to validate the model. Herein, two approaches were applied to correct DustTrak PM measurements to match the gravimetric measurements. The first approach involves a constant correction factor:

$\mathrm{PM}_{L R_{-} \text {corrected }}=a_{1} \mathrm{PM}_{D T}, a_{1}=\frac{\mathrm{PM}_{\text {grav }}}{\mathrm{PM}_{D T}}$

where $\mathrm{PM}_{D T}$ and $\mathrm{PM}_{\text {grav }}$ are PM measurements from DustTrak and gravimetric method, respectively; $a_{1}$ is the correction factor (i.e., the slope of regression) that was determined through the least-squares regression method comparing $\mathrm{PM}_{\text {grav }}$ against $\mathrm{PM}_{D T}$ measurements. In the second approach, the correction factor $\left(a_{1}\right)$ is a function of ambient $\mathrm{RH}$ :

$\mathrm{PM}_{R H_{-} \text {corrected }}=\left(a_{2}+b R H\right) \mathrm{PM}_{D T}$

where $a_{2}$ and $b$ are the intercept and slope parameters (as shown in Fig. S3) that were determined through least-squares regression using the correction factor $\left(a_{1}\right)$ values against the measured $\mathrm{RH}$ (expressed as a fraction of $100 \%$, e.g., RH $50 \%=0.5$ ). The regression parameters $a_{1}, a_{2}$, and $b$ 
were determined using XLSTAT ${ }^{\mathrm{TM}}$ add-in for Microsoft Excel (Addinsoft Inc., NY, USA) with the DustTrak, gravimetric PM data, and the RH data. The accuracy $(A)$ and precision of the measured and corrected DustTrak measurements were evaluated against the reference measurements ( $\mathrm{Li}$ et al., 2019):

$A=\frac{1}{n} \sum_{i=1}^{n} \frac{\mathrm{PM}_{D T, i}-\mathrm{PM}_{\text {grav }, i}}{\mathrm{PM}_{\text {grav }, i}}$

where $n$ is the number of data pairs, $\mathrm{PM}_{i}$ is the measured or corrected DustTrak measurement for the $i^{\text {th }}$ day and PM $\mathrm{M}_{\text {grav }, i}$ is the gravimetric measurement for the $i^{\text {th }}$ day. The precision was assessed in terms of coefficients of determination $\left(R^{2}\right)$, and root mean square error (RMSE) of the linear regression between readings of two measurement methods.

\section{RESULTS AND DISCUSSION}

The TSI DustTrak DRX aerosol monitor measured $\mathrm{PM}_{2.5}$ and $\mathrm{PM}_{10}$ concentrations (24-h average $\pm \mathrm{SD}$ ) of $81.2 \pm 48.5$ and $121.7 \pm 75.5 \mu \mathrm{g} \mathrm{m}{ }^{-3}$, respectively, having a significant variability during the study period (as shown in Fig. S1). In contrast, the filter-based gravimetric method reported $\mathrm{PM}_{2.5}$ and $\mathrm{PM}_{10}$ concentrations of $40.2 \pm 15.0$ and $145.7 \pm 64.0 \mu \mathrm{g} \mathrm{m}^{-3}$, respectively. The raw DustTrak $\mathrm{PM}_{2.5}$ measurements had an accuracy value of $105 \%$ and an $\mathrm{R}^{2}$ value of 0.90 (Fig. 1) compared to the gravimetric method. The intercept of the regression line was not significantly different from zero $(\alpha=-0.95, \mathrm{p}=0.96)$, but the slope was significantly higher than $1(\beta=2.02, \mathrm{p}$ $<0.001)$, suggesting significant and consistent proportional bias between these two methods. This is in line with previous studies that reported DustTrak $\mathrm{PM}_{2.5}$ concentrations 2-4 times higher than the readings of reference methods (Wang et al., 2009; McNamara et al., 2011; Both et al., 2013; Wang et al., 2016; Zhang et al., 2018; Li et al., 2019). The high precision suggests that the DustTrak monitor can be reliably used for characterizing $\mathrm{PM}_{2.5}$ mass concentrations when an appropriate correction factor is applied.

On the other hand, DustTrak underestimated $\mathrm{PM}_{10}$ mass concentrations (24-h average) by about $20 \%$ compared to the reference gravimetric method (Fig. 1). DustTrak $\mathrm{PM}_{10}$ measurements have better accuracy $(19.83 \%)$ but lower precision $\left(R^{2}=0.73\right)$ than $\mathrm{PM}_{2.5}$ measurements. Particularly, the precision of DustTrak $\mathrm{PM}_{10}$ readings is relatively low at higher $\mathrm{PM}_{10}$ levels $\left(>200 \mu \mathrm{g} \mathrm{m}^{-3}\right)$ as measured by the gravimetric method; those were mostly under dust storm conditions in this

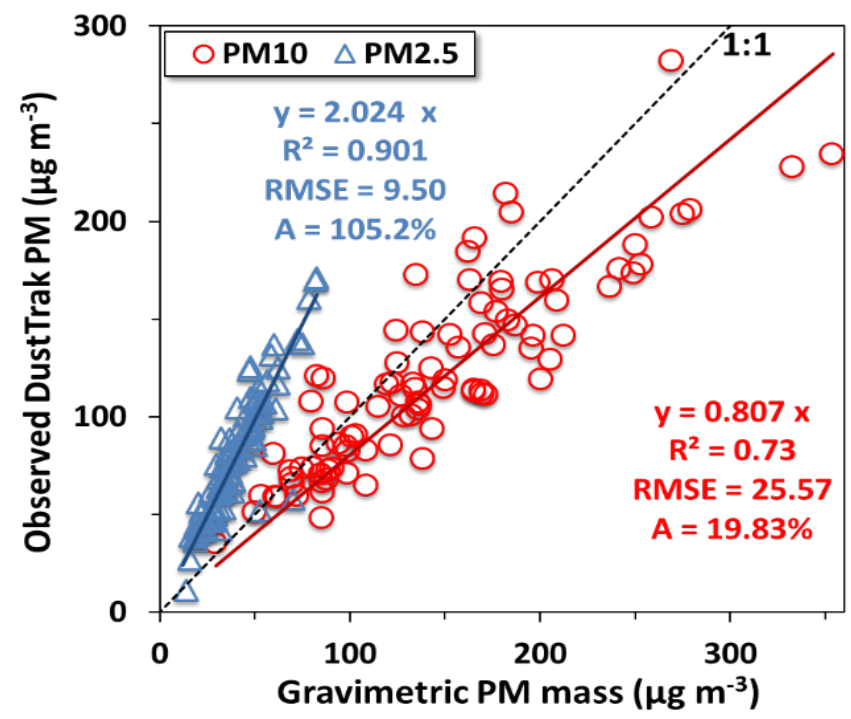

Fig. 1. Comparison of $\mathrm{PM}_{2.5}$ and $\mathrm{PM}_{10}$ 24-h average concentrations determined by DustTrak DRX and the reference gravimetric measurements (sampling period from May 18 to December 14, $2015, n=93$ ). Solid lines show linear fit, and the dashed line is the 1:1 ratio. 
desert environment (as shown in Fig. S1). The deviation of the highest $\mathrm{PM}_{10}$ concentrations from the regression line may be partially due to the coincidence error of single-particle sizing and counting by the DustTrak for larger particles (Wang et al., 2020). Airborne coarser particles (PM2.5-10) can have significantly different compositions than fine particles (Javed and Guo, 2020a). This discrepancy in measuring large-sized particles might also be related to the sampling efficiency and the lower mass scattering efficiency or specific photometric responses to coarser particles by the light-scattering DustTrak monitor (Wang et al., 2009; Liu et al., 2017). These are apparently the reasons that DustTrak compared differently to the gravimetric method in terms of $\mathrm{PM}_{2.5}$ and $\mathrm{PM}_{10}$.

The DustTrak PM10 measurements may have been affected by particle size, shape, and number concentration in this desert environment (Wang et al., 2016). It has also been reported that lightscattering-based monitors tend to measure slightly lower concentrations of large-sized particles than PM2.5 particles (Wang et al., 2009; Wang et al., 2016; Liu et al., 2017). Also, Zhang et al. (2018) reported that the relationship between PM mass concentration and light scattering is strongly dependent on particle size and, to a lesser extent, on PM composition. The measurement results reveal that the response of the DustTrak DRX monitor decreases as the particle size of the measuring aerosols increases and vice versa, so the correction of $\mathrm{PM}_{2.5}$ and $\mathrm{PM}_{10}$ measurements can be done by applying the appropriate correction factor separately for each size fraction. The correction parameters obtained in this study through a regression on the half model dataset (Fig. 2) and the full dataset (Figs. S2 and S3) are given in Table 1.
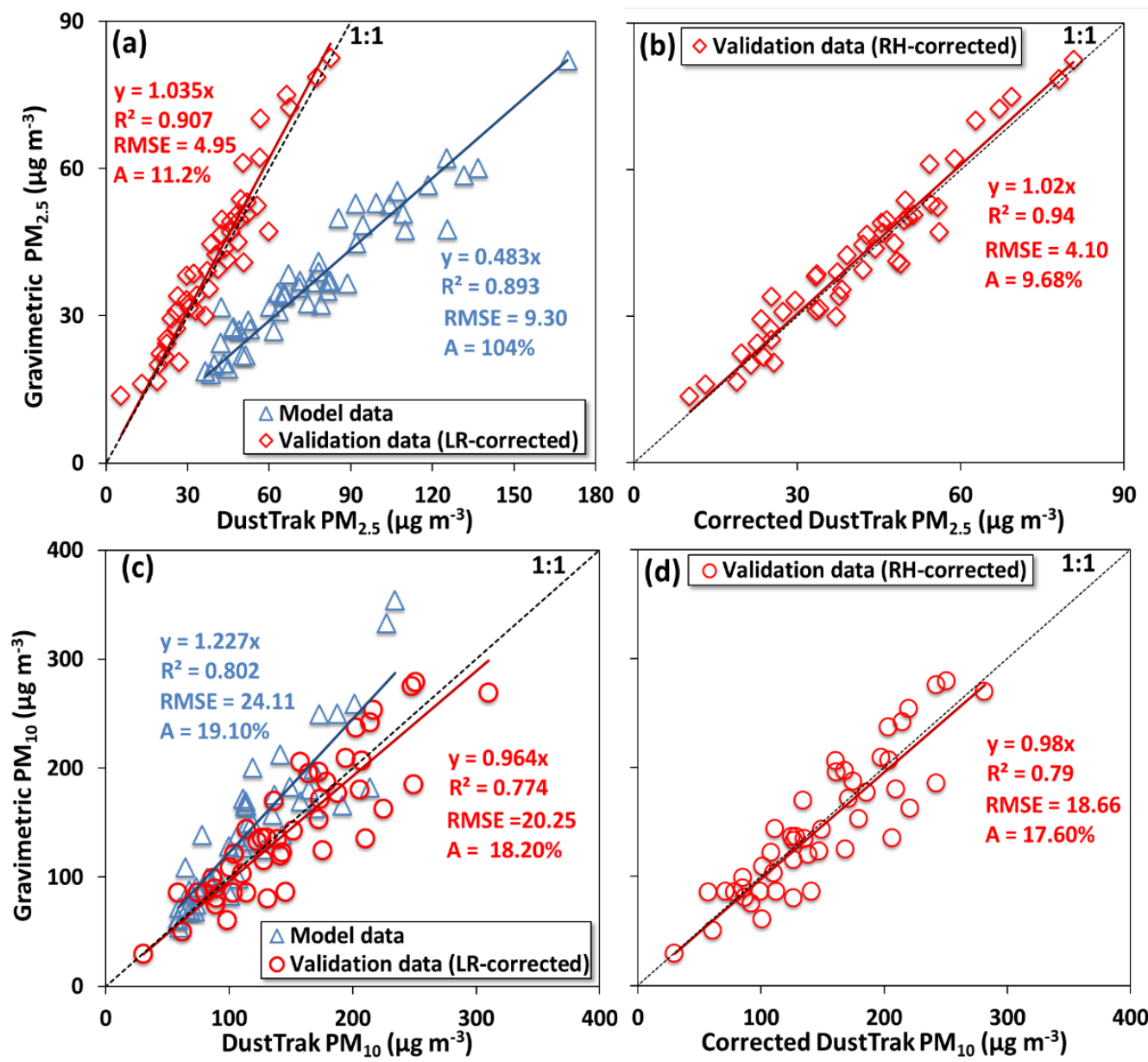

Fig. 2. The established correction models for DustTrak versus reference gravimetric measurements using one half of the dataset $(n=47)$ of $(a, b) P_{2.5}$ and $(c, d) P M_{10}$ and the models' validation on the second half of the dataset. The DustTrak data correction is based on $(a, c)$ the LR constant proportion method (Eq. (1)) and (b, d) the RH-adjusted proportion approach (Eq. (2)). Solid lines show linear fit, and the dashed line is the 1:1 ratio. 
The coefficient of 0.48 for the constant-proportion approach (for $\mathrm{PM}_{2.5}$ ) is in general agreement with previous studies (Wang et al., 2016; Zhang et al., 2018; Li et al., 2019), but higher than the manufacturer-recommended photometric correction factor of 0.38 for ambient $\mathrm{PM}_{2.5}$ aerosol (Wallace et al., 2011; TSI Inc., 2013). If this recommended correction factor was applied, the DustTrak $\mathrm{PM}_{2.5}$ concentrations were $23 \%$ lower than the gravimetric method. By following the TSI-recommended advanced calibration method (TSI Inc., 2012), the size calibration factor (SCF) of 1.375 is calculated using both $\mathrm{PM}_{2.5}$ and $\mathrm{PM}_{10}$ DustTrak and gravimetric measurements. This custom SCF can be programmed in the DustTrak DRX monitors by replacing the factory default value (1) of SCF in the user calibration settings for accurately measuring size-segregated mass concentrations of various size fractions. With the constant-proportion correction, the DustTrak $\mathrm{PM}_{2.5}$ reached an accuracy of $11 \%$ with RMSE of less than $5 \mu \mathrm{g} \mathrm{m}^{-3}$ (Fig. 2(a)); with the RHadjusted correction, DustTrak $\mathrm{PM}_{2.5}$ reached better accuracy with greater $\mathrm{R}^{2}(0.94)$ and lower RMSE (Fig. 2(b)). Similarly, with the constant-proportion correction, DustTrak $\mathrm{PM}_{10}$ also had improved the accuracy (Fig. 2(c)), but the RH-adjusted correction had no statistically significant further improvement, as shown in Fig. 2(d). The lesser effect of RH-adjusted correction on the accuracy of $\mathrm{PM}_{10}$ measurement might be related to the low influence of $\mathrm{RH}$ on coarse particles due to the variation of particle composition and size (Zhang et al., 2018).

A few previous studies reported correction factors for the DustTrak DRX in ambient conditions. For example, Wang et al. (2016) found a correction factor of 0.42 for DustTrak DRX PM 2.5 measurements in an indoor environment with $\mathrm{RH}$ conditions in the range of $13-68 \%$ and observed a relatively low ( $5 \%)$ impact of $\mathrm{RH}$ variation on DustTrak readings. Zhang et al. (2018) reported a correction factor of 0.51 for DustTrak DRX 1-h ambient $\mathrm{PM}_{2.5}$ under $\mathrm{RH}<40 \%$ by using a dryer. On the other hand, Li et al. (2019) reported correction factors (0.31-0.43) for DustTrak 30-min $\mathrm{PM}_{2.5}$ at higher $\mathrm{RH}$ conditions (50-90\%) and higher values of the correction factor (0.44-0.50) at $\mathrm{RH}<60 \%$. Consistent with this range of correction factors and $\mathrm{RH}$ conditions of the above studies, we have found the correction factor for the DustTrak $\mathrm{PM}_{2.5}$ measurements lying towards the upper end of this range under the prevailing dry-to-moderate $\mathrm{RH}(18-70 \%)$ conditions.

This study found that the DustTrak readings were significantly affected by the ambient $\mathrm{RH}$, and therefore, $\mathrm{RH}$ adjustment was considered for correcting the DustTrak measurements. The relationships between the correction factors of DustTrak 24-h $\mathrm{PM}_{2.5}$ and $\mathrm{PM}_{10}$ measurements and the ambient $\mathrm{RH}$ are shown in Fig. S3, and the obtained regression coefficients for $\mathrm{RH}$ adjustment are given in Table 1. Previous studies have also reported that PM mass concentrations measured by light-scattering instruments such as DustTrak increase with increasing RH due to the condensational growth of the hygroscopic particles (Liu et al., 2017; Jayaratne et al., 2018; Li et al., 2019).

It can also be seen in Fig. 3 that more significant concentration differences of PM $_{2.5}$ mass measured by the DustTrak and gravimetric method are typically associated with the high RH levels as well as higher particulate contents, which are hygroscopic constituents of fine particles and subject to the condensational growth at high RH (Wang et al., 2016; Liu et al., 2017; Zhang et al., 2018; Li et al., 2019). A significant positive correlation was found between the $\mathrm{PM}_{2.5}$ measurement difference and the ambient $\mathrm{RH}$ as well as $\mathrm{PM}_{2.5}$ constituents, including $\mathrm{SO}_{4}{ }^{2-}, \mathrm{NO}_{3}{ }^{-}, \mathrm{OC}$, and $\mathrm{EC}$ (Table S1). Since the DustTrak monitor is factory calibrated using an Arizona test dust that is mainly composed of mineral dust particles, it is not surprising that the DustTrak overestimation is correlated with particulate hygroscopic constituents. These aerosol components varying in

Table 1. Correction parameters obtained through regression.

\begin{tabular}{|c|c|c|c|}
\hline \multirow{2}{*}{ Correction approach } & \multirow{2}{*}{ Dataset used } & \multicolumn{2}{|c|}{ Parameters } \\
\hline & & $\mathrm{PM}_{2.5}$ & $\mathrm{PM}_{10}$ \\
\hline \multirow[t]{2}{*}{ Constant proportion } & Half $(n=47)^{*}$ & $a_{1}=0.483$ & $a_{1}=1.226$ \\
\hline & Full $(n=93)^{* *}$ & $a_{1}=0.489$ & $a_{1}=1.192$ \\
\hline \multirow[t]{2}{*}{$\mathrm{RH}$-adjusted proportion } & Half $(n=47)$ & $a_{2}=0.58 ; b=-0.17$ & $a_{2}=1.30 ; b=-0.19$ \\
\hline & Full $(n=93)$ & $a_{2}=0.57 ; b=-0.14$ & $a_{2}=1.33 ; b=-0.28$ \\
\hline
\end{tabular}

* One half of the dataset was used to calibrate the models, and the second half to validate the models.

${ }^{* *}$ In this case, the whole dataset was used to derive the model parameters for comparison purposes with those of half of the dataset. 


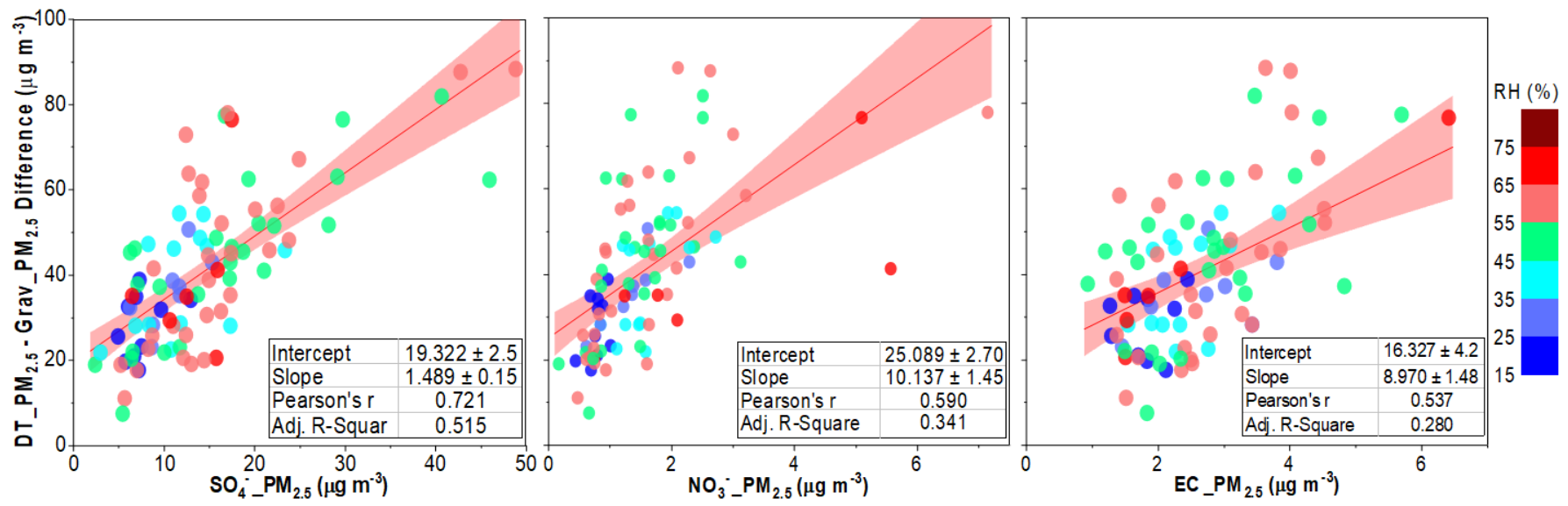

Fig. 3. Correlations of $\mathrm{PM}_{2.5}$ concentration difference between DustTrak and gravimetric measurements with concentrations of particulate $\mathrm{SO}_{4}{ }^{2-}, \mathrm{NO}_{3}{ }^{-}$and $\mathrm{EC}$ contents as a function of ambient $\mathrm{RH}$.

refractive indices can affect the light-scattering response of the optical instruments. For example, Zhang et al. (2018) have found a higher response of DustTrak DRX monitor for sulfate and organic particles with a higher refractive index for the optical measurements.

These results suggest that both correction approaches are capable of achieving accurate measurement corrections of DustTrak monitors deployed in dry environments. The constantproportion approach for DustTrak bias correction can be used in places where $\mathrm{RH}$ variation is relatively low, as reported in most previous studies (Chung et al., 2001; Kingham et al., 2006; Both et al., 2013; Wang et al., 2016). However, in areas where humidity varies greatly throughout the day, the DustTrak measurements without RH adjustment may lead to significant errors in reporting the actual concentration of atmospheric PM. It would be a feasible practice to record RH values along with the DustTrak measurements and then take $\mathrm{RH}$ into account to correct the measurement data, as proposed in this study. However, using a daily average RH correction against 24-h gravimetric measurements might not accurately represent the $\mathrm{RH}$ effect on the real-time measurement. The ambient $\mathrm{RH}$ has a diurnal cycle with significant variations during day and night time, and thereby, water uptake or evaporation by aerosol particles is different during the process of humidifying or drying (Javed and Guo, 2020b). Therefore, a better correction could be achieved in further studies using $\mathrm{RH}$ and reference PM data with higher time resolution. Furthermore, for reducing the $\mathrm{RH}$ effect, another way is to control ambient $\mathrm{RH}$ at monitors' sampling inlets to below a certain threshold using a dryer or heater such as used in BAM, TEOM instruments, and other photometers. For field calibration of aerosol monitors, it is essential to consider RH and aerosol properties for deriving the site-specific correction models for the DustTrak and other lightscattering monitors to reliably use these in air quality monitoring and regulatory applications.

\section{CONCLUSIONS}

This study assessed the performance of the DustTrak DRX aerosol monitor using the gravimetric technique as the reference method and identified appropriate bias correction factors for real-world operating conditions. In general, the DustTrak demonstrated high precision but low accuracy in tracking the $\mathrm{PM}_{2.5}$ and $\mathrm{PM}_{10}$ mass concentrations, simultaneously overestimating the former by a factor of $\sim 2$ (which is consistent with previously published research) and underestimating the latter by $\sim 20 \%$. Hence, to enhance the accuracy of these measurements, we developed two methods of calculating correction factors specific to each size fraction. The first approach, which attained an acceptable level of accuracy, uses a constant proportion, whereas the second, which achieved even better results, accounts for the RH. These factors can also be applied to readings provided by the DustTrak under comparable conditions, i.e., for aerosol with similar properties in similar environments. However, because the $\mathrm{RH}$ and the aerosol characteristics depend on the location, we recommend conducting calibration experiments in different environments under the influence of various parameters to develop site-specific correction factors for an individual unit. 
Overall, the DustTrak is a relatively economical and highly portable instrument that offers realtime monitoring with a low operating cost. However, it must be calibrated not only for a particular location but for a particular application in order to provide accurate PM mass measurements. Obtaining appropriate correction factors for each type of aerosol may allow us to utilize this device in reliable yet cost-effective and low-maintenance monitoring networks.

\section{ACKNOWLEDGMENTS}

This study was made possible in part by the NPRP award NPRP10-1230-160062 from the Qatar National Research Fund (a member of The Qatar Foundation).

\section{SUPPLEMENTARY MATERIAL}

Supplementary data associated with this article can be found in the online version at https://doi.org/10.4209/aaqr.200631

\section{REFERENCES}

Anderson, J.O., Thundiyil, J.G., Stolbach, A. (2012). Clearing the air: A review of the effects of particulate matter air pollution on human health. J. Med. Toxicol. 8, 166-175. https://doi.org/ 10.1007/s13181-011-0203-1

Apte, J.S., Kirchstetter, T.W., Reich, A.H., Deshpande, S.J., Kaushik, G., Chel, A., Marshall, J.D. Nazaroff, W.W. (2011). Concentrations of fine, ultrafine, and black carbon particles in autorickshaws in New Delhi, India. Atmos. Environ. 45, 4470-4480. https://doi.org/10.1016/j.atm osenv.2011.05.028

Both, A.F., Westerdahl, D., Fruin, S., Haryanto, B., Marshall, J.D. (2013). Exposure to carbon monoxide, fine particle mass, and ultrafine particle number in Jakarta, Indonesia: Effect of commute mode. Sci. Total Environ. 443, 965-972. https://doi.org/10.1016/j.scitotenv.2012.1 0.082

Chung, A., Chang, D.P., Kleeman, M.J., Perry, K.D., Cahill, T.A., Dutcher, D., McDougall, E.M., Stroud, K. (2001). Comparison of real-time instruments used to monitor airborne particulate matter. J. Air Waste Manage. Assoc. 51, 109-120. https://doi.org/10.1080/10473289.2001.10 464254

Javed, W., Guo, B. (2020a). Chemical characterization and source apportionment of fine and coarse atmospheric particulate matter in Doha, Qatar. Atmos. Pollut. Res. 12, 122-136. https://doi.org/10.1016/j.apr.2020.10.015

Javed, W., Guo, B. (2020b). Effect of relative humidity on dust removal performance of electrodynamic dust shield. J. Electrostat. 105, 103434. https://doi.org/10.1016/j.elstat.2020. 103434

Jayaratne, R., Liu, X.T., Thai, P., Dunbabin, M., Morawska, L. (2018). The influence of humidity on the performance of a low-cost air particle mass sensor and the effect of atmospheric fog. Atmos. Meas. Tech. 11, 4883-4890. https://doi.org/10.5194/amt-11-4883-2018

Kam, W., Cheung, K., Daher, N., Sioutas, C. (2011). Particulate matter (PM) concentrations in underground and ground-level rail systems of the Los Angeles Metro. Atmos. Environ. 45, 1506-1516. https://doi.org/10.1016/j.atmosenv.2010.12.049

Kingham, S., Durand, M., Aberkane, T., Harrison, J., Wilson, J.G., Epton, M. (2006). Winter comparison of TEOM, MiniVol and DustTrak $\mathrm{PM}_{10}$ monitors in a woodsmoke environment. Atmos. Environ. 40, 338-347. https://doi.org/10.1016/j.atmosenv.2005.09.042

Li, Z., Che, W., Frey, H.C., Lau, A.K.H., Lin, C. (2017). Characterization of PM2.5 exposure concentration in transport microenvironments using portable monitors. Environ. Pollut. 228, 433-442. https://doi.org/10.1016/j.envpol.2017.05.039

Li, Z., Che, W., Lau, A.K.H., Fung, J.C.H., Lin, C., Lu, X. (2019). A feasible experimental framework for field calibration of portable light-scattering aerosol monitors: Case of TSI DustTrak. Environ. Pollut. 255, 113136. https://doi.org/10.1016/j.envpol.2019.113136 
Liu, D., Zhang, Q., Jiang, J.K., Chen, D.R. (2017). Performance calibration of low-cost and portable particular matter (PM) sensors. J. Aerosol Sci. 112, 1-10. https://doi.org/10.1016/j.jaerosci.20 17.05.011

McNamara, M.L., Noonan, C.W., Ward, T.J. (2011). Correction factor for continuous monitoring of wood smoke fine particulate matter. Aerosol Air Qual. Res. 11, 315-322. https://doi.org/10. 4209/aaqr.2010.08.0072

TSI (2012). DUSTTRAK ${ }^{\text {TM }}$ DRX aerosol monitor calibration methods, Application Note EXPMN-005 (A4). https://www.tsi.com/getmedia/c17ffd47-4ade-4d09-8c54-58793ca8312e/EXPMN-005_DRX-

Calibration-A4?ext=.pdf

TSI (2013). Rationale for programming a photometer calibration factor (PCF) of 0.38 for ambient monitoring, Application Note EXPMN-007. https://tsi.com/getmedia/95751f37-537d-4cbf-95e1edc46a763764/EXPMN-007_A4_Rationale_Programming_PCF_Ambient_Monitoring?ext=.pdf

TSI (2019). DUSTTRAK ${ }^{\mathrm{TM}}$ DRX Aerosol Monitor Model 8533/8534/8533EP, Operation and Service Manual, P/N 6001898 Revision S. https://www.tsi.com/getmedia/3699890e-4adf-452f-9029f3725612d5d1/8533-8534-DustTrak_DRX-6001898-Manual-US?ext=.pdf

Wallace, L.A., Wheeler, A.J., Kearney, J., Van Ryswyk, K., You, H., Kulka, R.H., Rasmussen, P.E., Brook, J.R., Xu, X. (2011). Validation of continuous particle monitors for personal, indoor, and outdoor exposures. J. Exposure Sci. Environ. Epidemiol. 21, 49-64. https://doi.org/10.1038/j es. 2010.15

Wang, X., Zhou, H., Arnott, W.P., Meyer, M.E., Taylor, S., Firouzkouhi, H., Moosmüller, H., Chow, J.C., Watson, J.G. (2020). Evaluation of gas and particle sensors for detecting spacecraftrelevant fire emissions. Fire Saf. J. 113, 102977. https://doi.org/10.1016/j.firesaf.2020.102977

Wang, X.L., Chancellor, G., Evenstad, J., Farnsworth, J.E., Hase, A., Olson, G.M., Sreenath, A., Agarwal, J.K. (2009). A novel optical instrument for estimating size segregated aerosol mass concentration in real time. Aerosol Sci. Technol. 43, 939-950. https://doi.org/10.1080/027868 20903045141

Wang, Z., Calderon, L., Patton, A.P., Sorensen Allacci, M., Senick, J., Wener, R., Andrews, C.J., Mainelis, G. (2016). Comparison of real-time instruments and gravimetric method when measuring particulate matter in a residential building. J. Air Waste Manage. Assoc. 66, 11091120. https://doi.org/10.1080/10962247.2016.1201022

Wheeler, A.J., Gibson, M.D., MacNeill, M., Ward, T.J., Wallace, L.A., Kuchta, J., Seaboyer, M., Dabek-Zlotorzynska, E., Guernsey, J.R., Stieb, D.M. (2014). Impacts of air cleaners on indoor air quality in residences impacted by wood smoke. Environ. Sci. Technol. 48, 12157-12163. https://doi.org/10.1021/es503144h

Zhang, J., Marto, J.P., Schwab, J.J. (2018). Exploring the applicability and limitations of selected optical scattering instruments for PM mass measurement. Atmos. Meas. Tech. 11, 2995-3005. https://doi.org/10.5194/amt-11-2995-2018 